Check for updates

Cite this: RSC Adv., 2017, 7, 31123

Received 12th February 2017

Accepted 13th June 2017

DOI: $10.1039 / c 7 r a 01753 g$

rsc.li/rsc-advances

\section{Quantum dot based multiplex fluorescence quenching immune chromatographic strips for the simultaneous determination of sulfonamide and fluoroquinolone residues in chicken samples $\dagger$}

\author{
Gaoshuang Hu, (DD a Wei Sheng, ${ }^{a}$ Shijie Li, ${ }^{a}$ Yan Zhang, ${ }^{a}$ Junping Wang ${ }^{a}$ \\ and Shuo Wang*ab
}

A novel multiplex fluorescence quenching immune chromatographic strip (FQICS), using quantum dots (QDs) as a fluorescence donor, was proposed to screen sulfonamide (SA) and fluoroquinolone (FQ) residues in chicken samples, simultaneously. The principle of the proposed FQICS is on the basis of the fluorescence quenching effect, and colloidal gold was used as the fluorescence quencher. The limit of detection (LOD) in standard solution was $3 \mathrm{ng} \mathrm{mL}^{-1}$ and $0.6 \mathrm{ng} \mathrm{mL}^{-1}$ for sulfaquinoxaline (SQX) and norfloxacin (NOR), respectively, through visual detection using UV. For specificity analysis, results obtained indicated that this established method could be applied in broad-spectrum detection of SAs and FQs. Then the proposed FQICS was successfully applied in semiquantitative analysis of SQX (30 $\mu \mathrm{g}$ $\mathrm{kg}^{-1}$ ) and NOR $\left(6 \mu \mathrm{g} \mathrm{kg}^{-1}\right.$ ) in spiked chicken samples. The results obtained using the strips showed great agreement with those obtained using an ELISA kit, which indicates the good accuracy of the strips. As a conclusion, the proposed FQICS with a signal "turn-on" mode provides a suitable immunoassay for rapid, sensitive and simultaneous screening of SAs and FQs in chicken samples on-site.

\section{Introduction}

Sulfonamide (SA) and fluoroquinolone (FQ) belong to the class of antibiotics, and are widely used in preventing and treating animal infection worldwide..$^{1-3}$ However, the misuse of these chemicals caused their residues in food samples and results in potential hazards to human health, such as toxic reaction, allergic reaction and the increasing formation of antimicrobial resistance. ${ }^{2,4}$ To protect consumers against side effects related to SA or FQ residues, maximum residue limits (MRLs) in foods have been proposed. ${ }^{5,6}$

Various instrumental analytical methods were established to detect SAs and FQs in biological matrices, like capillary electrophoresis, $^{7-9}$ gas chromatography-tandem mass spectrometry, ${ }^{\mathbf{1 0}}$ liquid chromatography ${ }^{\mathbf{1 1 - 1 3}}$ and high-performance liquid chromatography coupled with mass spectrometry. ${ }^{\mathbf{1 4 - 1 9}}$ However, because these methods require expensive instruments, professional operators and complex procedures for pretreating samples, they are not suited for rapid screening of large numbers of samples and field assays. The enzyme linked immunosorbent assay (ELISA) $)^{\mathbf{1 , 2 0}}$ has

${ }^{a}$ Key Laboratory of Food Nutrition and Safety, Ministry of Education of China, Tianjin University of Science and Technology, Tianjin 300457, China. E-mail: s.wang@tust. edu.cn; Fax: +86 226091 2493; Tel: +86 2260912483

${ }^{b}$ Beijing Advanced Innovation Center for Food Nutrition and Human Health, Beijing Technology \& Business University (BTBU), Beijing 100048, China

$\dagger$ Electronic supplementary information (ESI) available. See DOI: 10.1039/c7ra01753g attracted much attention due to its high sample throughput and has been successfully applied in detecting SQX or FQs. However, it is still restricted by time-consuming incubation processes and multi-step operations.

Immune chromatographic strip (ICS), as one of the typical rapid on-site detection methods, had become a dominant pointof-care test technology for rapid screening due to its low costs, simple manipulation, and less analysis time. ${ }^{6,21,22}$ The conventional gold nanoparticles-based ICS usually have relative low sensitivity because of the limited signal amplification effect. ${ }^{23}$ Fluorescent particles-based ICS are characterized by enhanced sensitivity. ${ }^{24}$ However, the fluorescent particles have the peculiarity of sticking to the nitrocellulose (NC) membrane, due to their large size and tendency to agglomerate. ${ }^{25}$ Futhermore, this kind of ICS with signal "turn off" mode, still suffers from relatively not high sensitivity because of requiring large amount of target analytes to eliminate the signals on the test $(\mathrm{T})$ line. New immune chromatographic strip research efforts are focusing on the development of multi-analyte-residue analysis and the improvement of assay sensitivity.

Recently, some research groups ${ }^{25-30}$ reported a novel fluorescence-quenching ICS to improve the assay sensitivity. The fluorescence donors used in the above study were mainly fluorescein, fluorescein-doped microspheres or $\mathrm{Ru}(\text { phen })_{3}{ }^{2+}$-doped silica nanoparticles (RuNPs). QDs, as common fluorescent particles, have a high-fluorescence quantum yield, and a broad- 
excitation spectrum compared to organic dyes and fluorescent proteins, and have been frequently used as fluorescent labels in immunoassays. ${ }^{31,32}$

In this study, a rapid and sensitive fluorescent quenching immune chromatographic strips (FQICS) with turn-on signal was established for simultaneous determination of SAs and FQs residues in chicken samples on-site, using QDs (the emission wavelength was $532 \mathrm{~nm}$ under the excitation of $370 \mathrm{~nm}$ ) as fluorescent donors, and colloidal gold (the absorption wavelength was 520 $\mathrm{nm}$ ) as fluorescent quenchers. Most of the above-mentioned published paper stated that the primary cause of fluorescence quenching is attributed to the fluorescence resonance energy transfer (FRET) between AuNPs and fluorescein or fluoresceindoped microspheres. Therefore, we suggest the FRET maybe the main cause of fluorescence quenching in our proposed assay. Based on antibody-antigen interactions, the gold nanoparticles labeled antibody will be captured and coated on test $(\mathrm{T})$ line, and which will cause the fluorescence quenching of $\mathrm{T}$ line. And when free analytes were added, the fluorescence of $\mathrm{T}$ line cannot be completely quenched by gold nanoparticles, and will be visible. Assay results could be obtained by observing the fluorescence change present in the $\mathrm{T}$ line. This proposed method with turn-on model produced positive signals correlated with the detected targets, greatly improving the sensitivity. Besides, the proposed method showed advantage of multi-analyte-residue analysis onsite, shortening analytical time.

\section{Materials and methods}

\section{Materials and instrument}

SAs and FQs standards, chloroauric acid $\left(\mathrm{HAuCl}_{4}\right)$, ovalbumin (OVA, MW 45 kDa), 1-ethyl-3-[3-(dimethylamino)propyl] carbodiimide (EDC) were obtained from Sigma Aldrich Co. Ltd. (St Louis, USA). The QDs (ZnCdSe/Zns) was from Wuhan Jiayuan Quantum Dots Co., LTD, Wuhan, China. Anti-SQX and anti-NOR monoclonal antibody, SQX hapten were all produced in our laboratory. The commercial ELISA kit was from Reagent Technology Co. Ltd, Shenzhen, China. All the other reagents were of at least analytical grade and used without further treatment.

Absorbent pad, glass fiber membrane (SB 06), filter paper and polyvinyl chloride sheets were obtained from Kinbio Tech Co. (Shanghai, China). Three types of NC membranes (HF180, HF135 and HF90 with capillary flow rates of 180, 135 and $90 \mathrm{~s}$ per $4 \mathrm{~cm}$, respectively) were from Millipore (Bedford, MA, USA).

Ultraviolet-visible (UV-vis) absorption spectra were obtained with Shimadzu UV-2300 UV-vis spectrophotometer (Shimadzu, Japan). The fluorescence intensity of QDs was determined using F-4500 fluorescence spectrophotometer (Hitachi Co., Japan). The strips were determined by using a portable analyzer with a UV lamp (Shanghai Jiapeng technology co., China). The strips were prepared using a guillotine cutter (ZQ2000) and dispenser (HM3035) (Shanghai Kinbio Tech. Co., Ltd., China).

\section{Preparation of monoclonal antibody and coating antigen}

Sulfaquinoxaline (SQX) and norfloxacin (NOR) monoclonal antibody were purified using caprylic acid-ammonium sulfate method..$^{33}$ And the coating antigen (SQX-OVA and NOR-OVA) were prepared using activated ester methods. ${ }^{34,35}$

\section{Preparation of OVA-QDs complexes}

The OVA-QDs complexes were prepared according to previously described protocol with some modification. ${ }^{36,37} 100 \mu \mathrm{L}$ QDs (QD-COOH) ( $8 \mu \mathrm{M}$, dissolved in $50 \mathrm{mM} \mathrm{pH} 8.4$ borate buffer) was first diluted using $10 \mathrm{mM}$ sodium borate $(\mathrm{pH}$ 8.6) into a final concentration of $1 \mu \mathrm{M}$. Subsequently, $24 \mu \mathrm{L}$ EDC solution (10 $\mathrm{mg} \mathrm{mL}^{-1}$ in sodium borate) and $0.3 \mathrm{mg}$ OVA were added and stirred gently for $4 \mathrm{~h}$ at room temperature. Finally, the obtained mixture was concentrated to $100 \mu \mathrm{L}$ and collected off sunlight.

\section{Preparation of colloidal gold and gold labeled McAb}

The colloidal gold was produced referring to the previous method..$^{38,39}$ And the synthetic colloidal golds were uniformly spherical and presented high monodispersity with respective average sizes of approximately $20 \mathrm{~nm}$.

Then the gold labeled SQX McAb was prepared as follows. 10 $\mu \mathrm{L} 0.2 \mathrm{~mol} \mathrm{~mL}{ }^{-1} \mathrm{~K}_{2} \mathrm{CO}_{3}$ was appended to the prepared colloidal gold ( $1 \mathrm{~mL}$ ) to adjust its $\mathrm{pH}$ value to $8.5,18 \mu \mathrm{L}$ anti-SQX McAb at the concentration of $1 \mathrm{mg} \mathrm{mL}{ }^{-1}$ was then added. Afterwards, the reacted solution was kept at room temperature for $1 \mathrm{~h}$. Then $20 \%$ BSA solution $(20 \mu \mathrm{L})$ and $20 \%$ PEG-20 $000(10 \mu \mathrm{L})$ were added and incubated at room temperature for $15 \mathrm{~min}$ to block the unreacted surface of the colloidal gold. The solution was then centrifuged for $30 \mathrm{~min}\left(10000 \mathrm{rpm}, 4^{\circ} \mathrm{C}\right)$. The precipitate was re-suspended in dilution buffer and finally the gold labeled SQX McAb were obtained.

For the preparation of gold labeled NOR McAb, $15 \mu \mathrm{L} 0.2 \mathrm{~mol}$ $\mathrm{mL}^{-1} \mathrm{~K}_{2} \mathrm{CO}_{3}$ was appended to the prepared colloidal gold (1 $\mathrm{mL}$ ) to adjust its $\mathrm{pH}$ value to 9.0 , then $18 \mu \mathrm{L}$ anti-NOR McAb at the concentration of $1 \mathrm{mg} \mathrm{mL} \mathrm{m}^{-1}$ was added. Afterwards, the solution was placed without stirring at room temperature for $1 \mathrm{~h}$. The rest procedure was the same as the above procedure about preparing gold labeled SQX McAb.

\section{Construction of FQICS}

The test strip was made up of sample pad, conjugate pad, NC membrane, absorbent pad and PVC sheet from the top down. The PVC sheet $(30 \mathrm{~cm} \times 6 \mathrm{~cm})$ was applied as the backing plate, and the NC membrane $(2.5 \mathrm{~cm}$ wide) was placed on the center of the PVC sheet.

FQICS were developed referring to the work reported by $\mathrm{Fu}$ et al. and Shi et al., ${ }^{25,29}$ and performed as following. OVA-QDs complexes were diluted with a suitable amount of $0.01 \mathrm{M}, \mathrm{pH}$ 7.4 PBS. And $20 \mu \mathrm{L}$ of the OVA-QDs and NOR-OVA immobilized on NC membrane $\left(0.8 \mu \mathrm{L} \mathrm{cm}^{-1}\right)$ at lowest side to form $\mathrm{T} 2$ line, $20 \mu \mathrm{L}$ of the OVA-QDs and SQX-OVA were distributed on NC membrane $\left(0.8 \mu \mathrm{L} \mathrm{cm}^{-1}\right)$ in the middle to form the T1 line. 20 $\mu \mathrm{L}$ OVA-QDs $\left(0.8 \mu \mathrm{L} \mathrm{cm}^{-1}\right)$ was immobilized in the upper side to form the $\mathrm{C}$ line. The treated membrane was then dried at $37{ }^{\circ} \mathrm{C}$. Then the strips were assembled and cut into individual strips ( $0.37 \mathrm{~cm}$ wide). 


\section{Test principle}

For FRET, the emission spectrum of the donor must strongly overlap with the absorption spectrum of the acceptor, and the fluorescence donor must be sufficiently close to the fluorescence acceptor. In this proposed FQICA, as shown in Fig. 1B, the colloidal gold showed an absorbance wavelength of about $520 \mathrm{~nm}$, and the emission wavelength of QDs was $532 \mathrm{~nm}$ under the excitation of $370 \mathrm{~nm}$. A large spectrum overlap exists between the fluorescence donor and fluorescence acceptor, which offered a necessary condition for the occurrence of the FRET. Besides, the flexible chains of the antibody will then provide a suitable distance, so that the space between QDs and colloidal gold is short enough to cause FRET. Therefore, we inferred the FRET maybe the main cause of fluorescence quenching in our proposed assay.

The principle of the FQICS is illustrated in Fig. 1. Firstly, the sample was mixed with the gold labeled antibody mixture and then dropped onto the sample pad. Then the liquid sample containing gold labeled antibody mixture migrates via capillary action. If the added samples were negative without SQX or NOR, the mixtures reached the T2 line coated with NOR-OVA coating antigen and OVA-QDs, the gold labeled NOR McAb bind to NOR-OVA coating antigen. Since the QDs was simultaneously settled at the same place, the binding of gold labeled NOR McAb to NOR-OVA coating antigen will cause the fluorescent intensity on T2 line to be quenched and become weak. The liquid sample containing gold labeled SQX antibody continue migrating and when they reach the T1 line coated with SQX-OVA and OVAQDs, the gold labeled SQX McAb bind to SQX-OVA, and the same phenomenon will happen, causing the fluorescent at T1 line to be quenched. If a positive sample solution with NOR is added, firstly the free NOR will react with the gold labeled NOR McAb, which will cause less gold labeled NOR McAb to

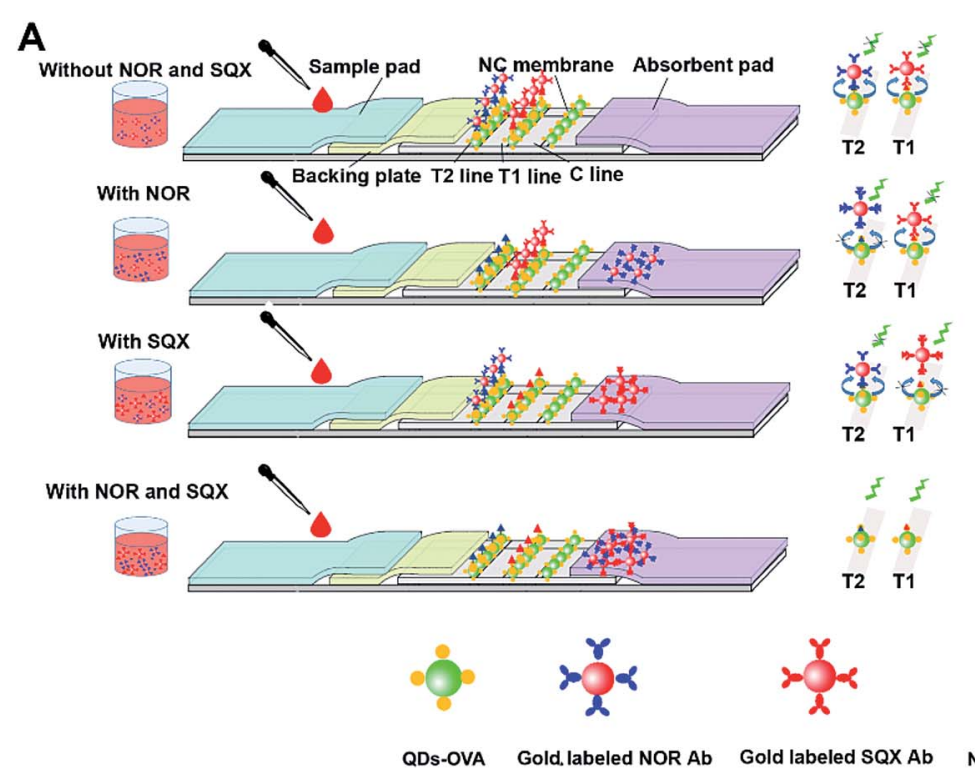

conjugate with NOR-OVA settled on T2 line. On this condition, the fluorescence at T2 line cannot be quenched completely and will be visible. If the added sample containing enough NOR, the fluorescence intensity at T2 line will recover to the maximum. And if a positive sample solution with SQX is added, which will cause less gold labeled SQX antibody combine with SQX-OVA settled on T1 line. On this condition, the fluorescence at T1 line will be visible. If sample solution containing both NOR and SQX, the fluorescence at both T2 line and T1 line will recover.

As a conclusion, the change of the fluorescence intensity at $\mathrm{T} 2$ and T1 lines reflect the quantity of the NOR and SQX. The proposed FQICS present a positive correlation relationship between the fluorescence intensity and the analyte concentration, allowing users to obtain visual results from weak fluorescent signals.

\section{Sample assay}

Chicken samples (certified without SQX or NOR) were spiked with a known amount of SQX $\left(0,30 \mu \mathrm{g} \mathrm{kg}{ }^{-1}\right)$, a known amount of $\operatorname{NOR}\left(0,6 \mu \mathrm{g} \mathrm{kg}^{-1}\right)$, and a known amount of SQX $(0,30 \mu \mathrm{g}$ $\left.\mathrm{kg}^{-1}\right)$ and NOR (0, $\left.6 \mu \mathrm{g} \mathrm{kg}^{-1}\right)$ mixture, respectively, and kept frozen until use. $1.0 \mathrm{~g}$ sample were placed in $50 \mathrm{~mL}$ centrifuge tube, subsequently $0.1 \mathrm{~mol} \mathrm{~L}^{-1} \mathrm{NaOH}(0.2 \mathrm{~mL})$ and methanol $(0.8 \mathrm{~mL})$ was added to each tube. The mixture was then treated with vigorous vortex oscillation and extracted for $5 \mathrm{~min}$. After centrifugation (10 $000 \mathrm{rpm}, 15 \mathrm{~min}, 4{ }^{\circ} \mathrm{C}$ ), the supernatant was collected and diluted with PBST at a ratio of $1: 10$, and then used for analysis.

\section{Results and discussion}

\section{Optimization of the FQICS assay}

The conditions of the FQICS assay (as shown in Table S1†) were optimized in this study to achieve the optimal detection

Fig. 1 Schematic illustration of the fluorescent quenching immune chromatographic strips (FQICS) (A). And fluorescence spectrum of QDs under an excitation of $370 \mathrm{~nm}$, and UV-Vis absorption spectrum of colloidal gold (B).
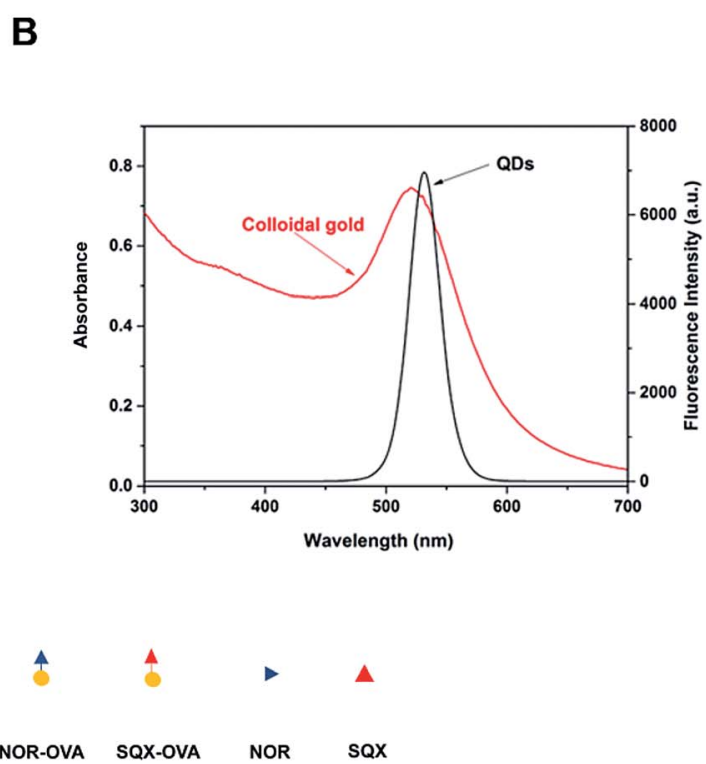
performance. NC membrane and dilution ratio of the coating antigen, gold labeled antibody and fluorescence labels (OVAQDs), each has a significant effect on the strip sensitivity and performance in this study. Three different types of NC membranes (capillary flow rate of $90 \mathrm{~s} / 4 \mathrm{~cm}, 135 \mathrm{~s} / 4 \mathrm{~cm}$ and 180 $\mathrm{s} / 4 \mathrm{~cm}$ ) were tested, and the membrane of $135 \mathrm{~s} / 4 \mathrm{~cm}$ was found to be the most suitable one, it might be because the membrane of $135 \mathrm{~s} / 4 \mathrm{~cm}$ provides the most suitable capillary flow rate, thereby resulting in the most suitable reaction time and allowing the assay achieving good sensitivity. The dilution ratio of fluorescence labels OVA-QDs were 1 : 8 on the T1, T2 and C line, because enough fluorescence intensity for visual signal could be ensured on this condition by the naked eye under the portable UV lamp at $370 \mathrm{~nm}$. On T2 line, OVA-QDs mixed with NOR-OVA was settled, and the dilution ratio and solution of NOR-OVA was $1: 8$ in PBS. On T1 line, OVA-QDs mixed with SQX-OVA was settled, and the dilution ratio and solution of the SQX-OVA was 1 : 10 in PBS. The dilution ratio of gold labeled NOR McAb was $1: 100$, and the dilution ratio of gold labeled SQX McAb was $1: 50$. It was because the antibody and antigen will react fully under these conditions and the fluorescence on $\mathrm{T} 1$ and $\mathrm{T} 2$ line will be totally quenched. At C line, OVA-QDs mixed with PBS containing $3 \mathrm{mg} \mathrm{mL}^{-1}$ OVA was settled, and the function of OVA was to fix the same amount of OVA-QDs to C line as the amount of OVA-QDs on T1 and T2 line, allowing the same fluorescence intensity on all the three lines. Under the above conditions, the assay can not only achieve reliability of visual detection, but also present good sensitivity.

\section{Visual assessment of the FQICS}

The visual LOD for the proposed FQICS was defined as the minimum concentration of NOR and SQX resulting in the appearance of fluorescence band on $\mathrm{T} 2$ and $\mathrm{T} 1$ line of the strip by the naked eye under the portable UV lamp at $370 \mathrm{~nm}$. Different concentration of $\operatorname{NOR}\left(0,0.6,2 \mathrm{ng} \mathrm{mL}{ }^{-1}\right)$ and different concentration of SQX $\left(0,3,10 \mathrm{ng} \mathrm{mL}^{-1}\right)$ were studied to determine the sensitivity of FQICS in PBST (PBS buffer containing $0.05 \%$ Tween-20). As shown in Fig. 2, the concentration of the targets inversely correlated with the fluorescence intensity on the test lines. Faint bright fluorescence band appeared on $\mathrm{T} 2$ line at $0.6 \mathrm{ng} \mathrm{mL}{ }^{-1}$ of NOR and on T1 line at $3 \mathrm{ng} \mathrm{mL}^{-1}$ of SQX. Accordingly, three bands appeared indicating that the concentration of NOR and SQX was at or above $0.6 \mathrm{ng} \mathrm{mL}^{-1}$ and $3 \mathrm{ng}$ $\mathrm{mL}^{-1}$, respectively. If only the fluorescence on $\mathrm{C}$ line and $\mathrm{T} 2$ band appeared, indicating that the concentration of NOR at or above $0.6 \mathrm{ng} \mathrm{mL} \mathrm{mL}^{-1}$, while the amount of SQX was below $3 \mathrm{ng}$ $\mathrm{mL}^{-1}$. And if the fluorescence on $\mathrm{C}$ line and $\mathrm{T} 1$ band appeared, indicating that the concentration of SQX at or above $3 \mathrm{ng} \mathrm{mL} \mathrm{mL}^{-1}$, while the concentration of NOR was less than $0.6 \mathrm{ng} \mathrm{mL}^{-1}$.

\section{Specificity}

Specificity of the FQICS was tested by evaluating the reactivity of the antibody with other analogues. In this study, thirteen analogues of SAs type were studied as follows: sulfachloropyridazine, sulfamethoxypyridazine, sulfamethoxazole, sulfametoxydiazine, sulfadimethoxine, sulfathiazole,

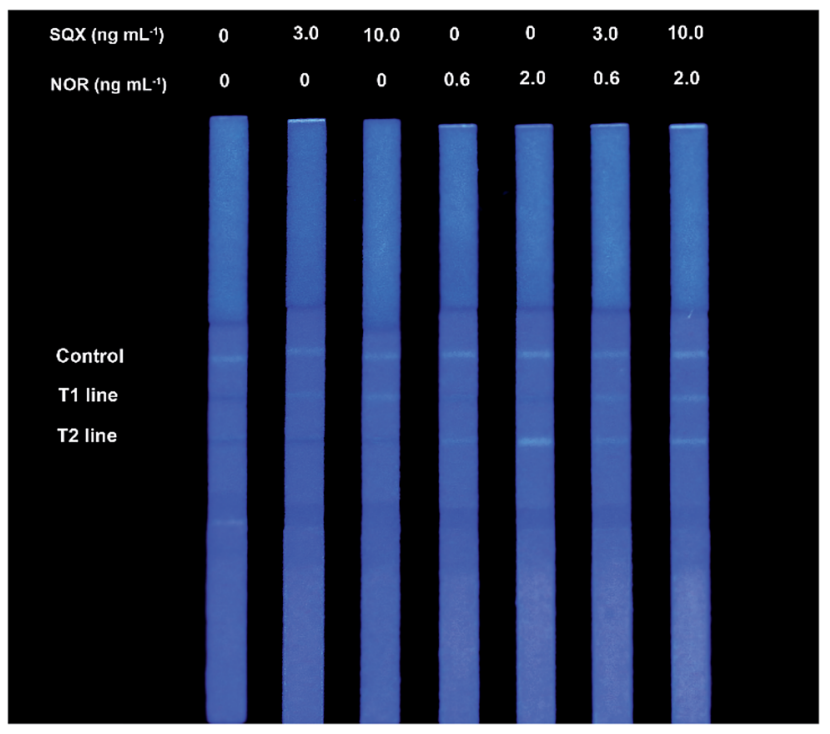

Fig. 2 Sensitivity analysis in PBST solution with different NOR and SQX concentrations using the proposed FQICS.

sulfapyridine, sulfamoxol, sulfamethoxazole, sulfadiazine, sulfisoxazole, sulfadimidine, sulfadoxine. The concentration of each compound at 10, 50, and/or $1000 \mathrm{ng} \mathrm{mL} \mathrm{m}^{-1}$ in PBST were applied for the strips, as shown on Fig. 3A. The T1 line showed faint bright fluorescence recovery when the concentration of sulfachloropyridazine, sulfamethoxypyridazine, sulfamethoxazole and sulfametoxydiazine was $10 \mathrm{ng} \mathrm{mL}^{-1}$, respectively. For sulfadimethoxine, sulfathiazole, and sulfapyridine, at concentrations of $50 \mathrm{ng} \mathrm{mL}^{-1}$, the fluorescence intensity of $\mathrm{T} 1$ line showed recovery. While for the other six analogues, even at 1000 $\mathrm{ng} \mathrm{mL}^{-1}$, no obvious fluorescence recovery on $\mathrm{T} 1$ line was observed. The obtained results demonstrated that the strips can be applied in not only detecting SQX, but also detecting seven other SAs, at certain concentration.

Eleven analogues of FQs were also studied. As shown in Fig. 3B, the concentration of each compound at 5, 20, and/or $1000 \mathrm{ng} \mathrm{mL} \mathrm{mL}^{-1}$ in PBST were applied for the strips. The fluorescence recovery appeared on $\mathrm{T} 2$ line, when the concentration of ciprofloxacin, nalidixic acid, enrofloxacin, ofloxacin, oxilinic acid, flumequine, fleroxacin and lomefloxacin was $5 \mathrm{ng} \mathrm{mL} \mathrm{m}^{-1}$, respectively. For enoxacin, marbofloxacin at concentrations of $20 \mathrm{ng} \mathrm{mL} \mathrm{m}^{-1}$, the fluorescence intensity of $\mathrm{T} 2$ line showed recovery. For cinoxacin, at concentrations of $1000 \mathrm{ng} \mathrm{mL}^{-1}$, only week fluorescence recovery was observed on $\mathrm{T} 2$ line. The results indicated that the strips can be applied in not only detecting NOR, but also detecting other ten other FQs, at certain concentrations.

As a conclusion, the FQICS proposed in this study can be applied for qualitative detection of 8 SAs and 11 FQs, due to the broad spectra property of antibody prepared by our lab.

\section{Samples analysis}

Commercial ELISA kit was used to verify the accuracy of the FQICS (NOR and SQX were taken for example). As shown in 


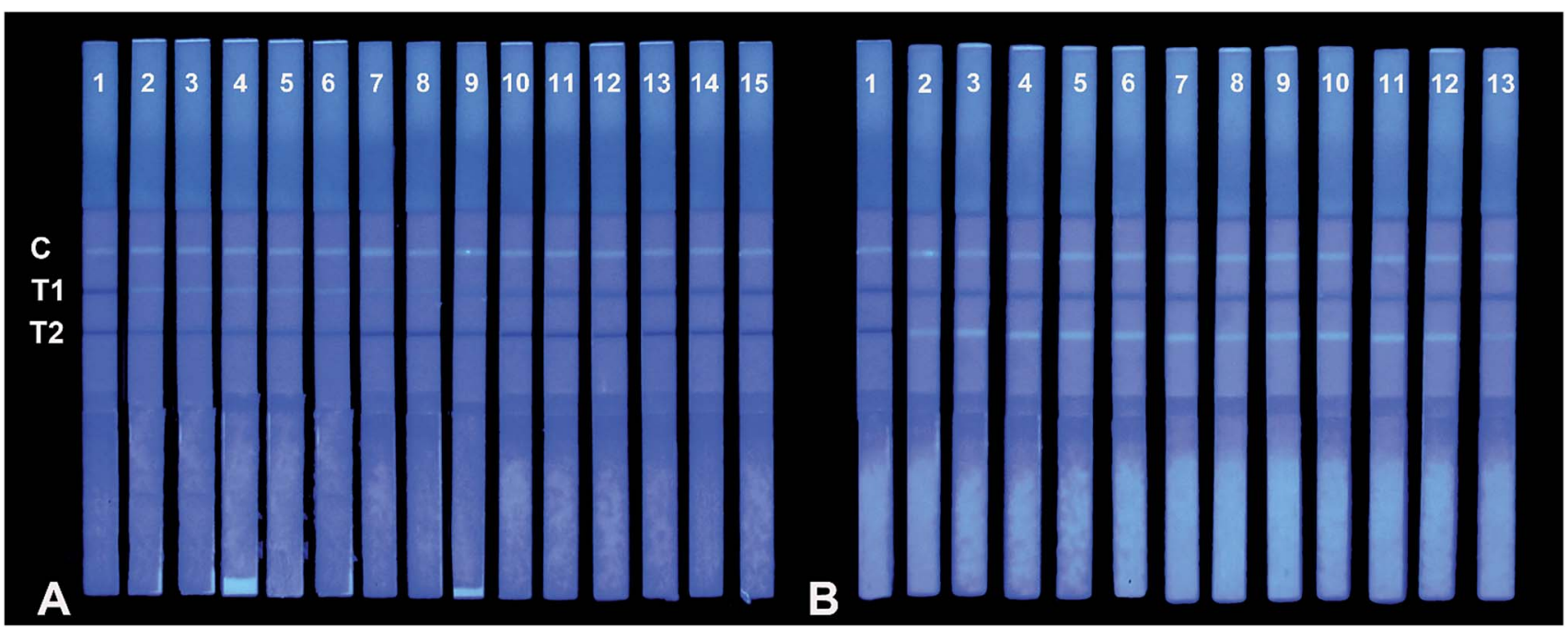

Fig. 3 Specificity analysis using the QDs-based FQICS. (A) Compounds from left to right, (1) PBST, (2) SQX (3 ng mL ${ }^{-1}$ ), (3) sulfachloropyridazine $\left(10 \mathrm{ng} \mathrm{mL}^{-1}\right)$, (4) sulfamethoxypyridazine $\left(10 \mathrm{ng} \mathrm{mL}^{-1}\right)$, (5) sulfamethoxazole $\left(10 \mathrm{ng} \mathrm{mL}^{-1}\right)$ (6) sulfametoxydiazine (10 ng mL $\mathrm{mb}^{-1}$ ), (7) sulfadimethoxine (50 ng mL$\left.{ }^{-1}\right)$, (8) sulfathiazole $\left(50 \mathrm{ng} \mathrm{mL}^{-1}\right)$, (9) sulfapyridine (50 ng mL ${ }^{-1}$ ), (10) sulfamoxol, (11) sulfamethoxazole, (12) sulfadiazine, (13) sulfisoxazole, (14) sulfadimidine, (15) sulfadoxine, and their concentration were all $1000 \mathrm{ng} \mathrm{mL}^{-1}$. (B) Compounds from left to right: (1) PBST, (2) NOR $\left(0.6 \mathrm{ng} \mathrm{mL}^{-1}\right)$, (3) ciprofloxacin $\left(5 \mathrm{ng} \mathrm{mL}^{-1}\right)$, (4) nalidixic acid $\left(5 \mathrm{ng} \mathrm{mL}^{-1}\right)$, (5) enrofloxacin (5 $\left.\mathrm{ng} \mathrm{mL}^{-1}\right)$, (6) ofloxacin (5 ng mL $\mathrm{mL}^{-1}$ ), (7) oxilinic

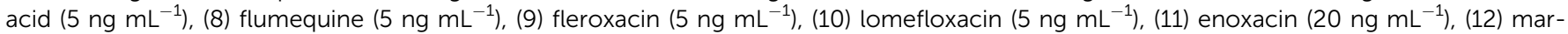
bofloxacin (20 $\mathrm{ng} \mathrm{mL}^{-1}$ ), (13) cinoxacin (1000 $\mathrm{ng} \mathrm{mL}^{-1}$ ).

Table 1, when the concentration of NOR reached to $6 \mu \mathrm{g} \mathrm{kg}^{-1}$, positive results $(+)$ on $\mathrm{T} 2$ line could be observed by using the FQICS. And when the concentration of SQX reached to $30 \mu \mathrm{g}$ $\mathrm{kg}^{-1}$, positive results $(+)$ on $\mathrm{T} 1$ line could be observed by using the FQICS. Besides, all the results obtained using the strips were in good agreement with those performed using ELISA kits, indicating the high accuracies of the proposed assay. It is worth noted that, the proposed QDs-based FQICS could be applied in simultaneous detection of SQX and NOR in chicken samples.

Table 1 Recoveries of the spiked chicken samples using comercial ELISA kits and the proposed FQICS ${ }^{a}$

\begin{tabular}{|c|c|c|c|c|c|}
\hline \multicolumn{2}{|c|}{ Spiked analytes } & \multicolumn{2}{|c|}{ Comercial ELISA kits $^{c}$} & \multicolumn{2}{|c|}{$\begin{array}{l}\text { QDs-based } \\
\text { FQICS }^{d}\end{array}$} \\
\hline $\begin{array}{l}\text { SQX } \\
\left(\mu \mathrm{gg}^{-1}\right)\end{array}$ & $\begin{array}{l}\text { NOR } \\
\left(\mu g \mathrm{~kg}^{-1}\right)\end{array}$ & $\begin{array}{l}\text { SQX kits } \\
\left(\mu \mathrm{g} \mathrm{kg}{ }^{-1}\right) \\
(n=3)\end{array}$ & $\begin{array}{l}\text { NOR kits } \\
\left.(\mu \mathrm{g} \mathrm{kg})^{-1}\right)(n=3)\end{array}$ & $\begin{array}{l}\text { T1 line } \\
(n=3)\end{array}$ & $\begin{array}{l}\text { T2 line } \\
(n=3)\end{array}$ \\
\hline 0 & 0 & $\mathrm{ND}^{b}$ & $\mathrm{ND}^{b}$ &,,--- &,,--- \\
\hline 30.00 & 0 & $\begin{array}{l}27.26 \pm \\
0.79\end{array}$ & $\mathrm{ND}^{b}$ &,,+++ &,,--- \\
\hline 0 & 0 & $\mathrm{ND}^{b}$ & $\mathrm{ND}^{b}$ &,,--- &,,--- \\
\hline 0 & 6.00 & $\mathrm{ND}^{b}$ & $6.87 \pm 1.79$ &,,--- &,,+++ \\
\hline 0 & 0 & $\mathrm{ND}^{b}$ & $\mathrm{ND}^{b}$ &,,--- &,,--- \\
\hline 30.00 & 6.00 & $\begin{array}{l}28.80 \pm \\
1.30\end{array}$ & $7.11 \pm 0.32$ &,,+++ &,,+++ \\
\hline
\end{tabular}

${ }^{a}$ Visual assessment of $\mathrm{T}$ line: $(-)$ negative result, $(+)$ positive result. ${ }^{b}$ Not detected. ${ }^{c}$ Two kinds of comercial ELISA kits were needed to detect these two drugs (NOR and SQX) in chicken samples. ${ }^{d}$ The proposed FQICS could be applied in simultaneous detection of SAs and FQs in chicken samples according to the occurrence of fluorescence signals on $\mathrm{T} 1$ and $\mathrm{T} 2$ line.
However, two kinds of commercial ELISA kits were needed to detect these two drugs (SQX and NOR).

\section{Conclusions}

In summary, a multiplex sensitive FQICS based on the fluorescence quenching effect was established to determine SAs and FQs in chicken samples, simultaneously. The FQICS presented a turn-on mode method and allowed users to obtain visual results from weak fluorescent signals, greatly improving the sensitivity of the assay. The developed FQICS was then successfully applied in sensitive and rapid detection of SQX and NOR in chicken samples. The results showed good agreement between the developed FQICS and the ELISA kits. In addition, the assay was simple to perform, and the detection could be completed within $10 \mathrm{~min}$. The proposed method provides a sensitive, fast, on-site, and user-friendly method for detecting SAs and FQs present in chicken samples, simultaneously.

\section{Acknowledgements}

The authors are grateful for financial support from International Science and Technology Cooperation Program of China (Project No. 2014DFR30350), the National Key Research and Development Program of China (Project No. 2016YFD0401204), and the Tianjin Municipal Science and Technology Commission (Project No. 16PTSYJC00130).

\section{Notes and references}

1 J. Adrian, H. Font, J. M. Diserens, F. Sanchez-Baeza and M. P. Marco, J. Agric. Food Chem., 2009, 57, 385-394. 
2 B. Agrawal, P. Chandra, R. N. Goyal and Y. B. Shim, Biosens. Bioelectron., 2013, 47, 307-312.

3 Z. Meng, Z. Shi, S. Liang, X. Dong, H. Li and H. Sun, Food Chem., 2015, 174, 597-605.

4 Q. Zhou and Z. Fang, Talanta, 2015, 141, 170-174.

5 S. Lu, Y. Zhang, J. Liu, C. Zhao, W. Liu and R. Xi, J. Agric. Food Chem., 2006, 54, 6995-7000.

6 X. Wang, K. Li, D. Shi, N. Xiong, X. Jin, J. Yi and D. Bi, J. Agric. Food Chem., 2007, 55, 2072-2078.

7 C. Cheng, C. Fu and C. Chou, J. Chromatogr. B: Anal. Technol. Biomed. Life Sci., 2007, 856, 381-385.

8 J. J. Soto-Chinchilla, A. M. Garcia-Campana and L. GamizGracia, Electrophoresis, 2007, 28, 4164-4172.

9 R. M. Tubaon, P. R. Haddad and J. P. Quirino, J. Chromatogr. A, 2014, 1349, 129-134.

10 T. Portoles, L. E. Rosales, J. V. Sancho, F. Javier Santos and E. Moyanol, J. Chromatogr. A, 2015, 1413, 107-116.

11 J. Sousa, G. Alves, A. Fortuna and A. Falcao, Anal. Bioanal. Chem., 2012, 403, 93-129.

12 G. Wan, H. Cui, Y. Pan, P. Zheng and L. Liu, J. Chromatogr. B: Anal. Technol. Biomed. Life Sci., 2006, 843, 1-9.

13 Y. Wen, M. Zhang, Q. Zhao and Y. Feng, J. Agric. Food Chem., 2005, 53, 8468-8473.

14 M. Denadai and Q. B. Cass, J. Chromatogr. A, 2015, 1418, 177184.

15 K. Mitani and H. Kataoka, Anal. Chim. Acta, 2006, 562, 16-22.

16 J. M. Storey, S. B. Clark, A. S. Johnson, W. C. Andersen, S. B. Turnipseed, J. J. Lohne, R. J. Burger, P. R. Ayres, J. R. Carr and M. R. Madson, J. Chromatogr. B: Anal. Technol. Biomed. Life Sci., 2014, 972, 38-47.

17 N. F. Tetzner, M. G. Maniero, C. Rodrigues-Silva and S. Rath, J. Chromatogr. A, 2016, 1452, 89-97.

18 R. D. Yeole, V. L. Kulkarni, S. B. Latad, R. P. Chavan, Y. Chugh, M. V. Patel and H. F. Khorakiwala, J. Chromatogr. B: Anal. Technol. Biomed. Life Sci., 2007, 846, 306-312.

19 Z. Zhang, X. Li, S. Ding, H. Jiang, J. Shen and X. Xia, Food Chem., 2016, 204, 252-262.

20 L. Zhang, J. Jiang, G. Li, Z. Wang, X. Yang, J. Ma, H. Zhang, H. Huang and X. Liu, J. Food, Agric. Environ., 2011, 9, 113120.

21 S. Han, T. Zhou, B. Yin and P. He, Anal. Chim. Acta, 2016, 927, 64-71.
22 M. J. Raeisossadati, N. M. Danesh, F. Borna, M. Gholamzad, M. Ramezani, K. Abnous and S. M. Taghdisi, Biosens. Bioelectron., 2016, 86, 235-246.

23 Y. Chen, Q. Chen, M. Han, J. Liu, P. Zhao, L. He, Y. Zhang, Y. Niu, W. Yang and L. Zhang, Biosens. Bioelectron., 2016, 79, 430-434.

24 H. Qu, Y. Zhang, B. Qu, H. Kong, G. Qin, S. Liu, J. Cheng, Q. Wang and Y. Zhao, Biosens. Bioelectron., 2016, 81, 358362.

25 Q. Fu, Y. Tang, C. Shi, X. Zhang, J. Xiang and X. Liu, Biosens. Bioelectron., 2013, 49, 399-402.

26 X. Chen, Y. Xu, J. Yu, J. Li, X. Zhou, C. Wu, Q. Ji, Y. Ren, L. Wang, Z. Huang, H. Zhuang, L. Piao, R. Head, Y. Wang and J. Lou, Anal. Chim. Acta, 2014, 841, 44-50.

27 Q. Fu, J. Liang, C. Lan, K. Zhou, C. Shi and Y. Tang, Sens. Actuators, B, 2014, 203, 683-689.

28 H. Jiang, X. Li, Y. Xiong, K. Pei, L. Nie and Y. Xiong, Toxins, 2017, 9, 83.

29 C. Shi, N. Deng, J. Liang, K. Zhou, Q. Fu and Y. Tang, Anal. Chim. Acta, 2015, 854, 202-208.

30 G. Zhang, M. Chen, D. Liu, Y. Xiong, R. Feng, P. Zhong and W. Lai, Anal. Methods, 2016, 8, 627-631.

31 C. Wang, F. Hou and Y. Ma, Biosens. Bioelectron., 2015, 68, 156-162.

32 L. Zhou, A. Zhu, X. Lou, D. Song, R. Yang, H. Shi and F. Long, Anal. Chim. Acta, 2016, 905, 140-148.

33 Y. Xu, J. H. Liu, J. Wang, J. Zhang and B.-Y. Yu, Chin. J. Nat. Med., 2014, 12, 794-799.

34 G. Hu, W. Sheng, Y. Zhang, J. Wang, X. Wu and S. Wang, J. Agric. Food Chem., 2016, 64, 3908-3915.

$35 \mathrm{G}$. Hu, W. Sheng, Y. Zhang, X. Wu and S. Wang, Anal. Bioanal. Chem., 2015, 407, 8487-8496.

36 V. Medawar, G. A. Messina, M. Fernandez-Baldo, J. Raba and S. V. Pereira, Microchem. J., 2017, 130, 436-441.

37 H. Qu, Y. Zhang, B. Qu, H. Kong, G. Qin, S. Liu, J. Cheng, Q. Wang and Y. Zhao, Biosens. Bioelectron., 2016, 81, 358362.

38 Y. Na, W. Sheng, M. Yuan, L. Li, B. Liu, Y. Zhang and S. Wang, Microchim. Acta, 2012, 177, 177-184.

39 W. Sheng, Y. Li, X. Xu, M. Yuan and S. Wang, Microchim. Acta, 2011, 173, 307-316. 